\title{
A VARIAÇÃO DO /S/ EM CODA SILÁBICA NO FALAR DOS MORADORES DA CIDADE DE TONANTINS, NO AMAZONAS
}

\author{
THE VARIATION OF /S/ IN SILABICA CODA IN TONANTINS \\ RESIDENTS' SPEECH, IN AMAZONAS
}

Flávia Santos Martins ${ }^{1}$ http://lattes.cnpq.br/7228755170686280

\author{
Vanessa Lara de Souza Santos ${ }^{2}$ \\ http://lattes.cnpq.br/4696496779798498
}

RESUMO: Este artigo, de cunho variacionista, teve como objetivo geral investigar a variação do /S/ em coda silábica no falar amazonense, a partir de dados dos moradores de Tonantins (AM), a fim de contribuir para o conhecimento das áreas dialetais brasileiras. Para isso, foi descrito quais as variantes do fenômeno em foco caracterizam o falar dos habitantes da cidade investigada, assim como foram analisados quais grupos de fatores linguísticos (tonicidade e contexto seguinte) e extralinguísticos (idade, escolaridade, sexo, mobilidade e localismo) atuaram ou não sobre as variantes descritas. Para o desenvolvimento da pesquisa, utilizou-se parte dos dados coletados por Martins (2013) para sua tese de doutoramento. O corpus utilizado foi composto por 12 informantes, estratificados de acordo com idade, sexo e escolaridade. No total, foram analisadas 3.888 realizações do /S/ em coda silábica no programa GoldVarbX. A análise dos dados mostrou que a variante alveopalatal $(66,3 \%)$ foi a mais realizada pelos tonantinenses entrevistados, além de mostrar as variáveis independentes linguísticas e extralinguísticas que favoreceram o uso dessa variante, na seguinte ordem de seleção: contexto seguinte, sexo, mobilidade, idade e ocupação.

Palavras-chave: Variação; /S/ em coda silábica; Tonantins (AM).

ABSTRACT: This article, of a variationist nature, had the general objective of investigating the variation of /S/ in syllabic coda in Amazonian speech, based on data from the residents of Tonantins, in order to contribute to the knowledge of Brazilian dialect areas. For that, it was described which variants of the phenomenon in focus characterize the speech of the inhabitants of the investigated city, as well as which groups of linguistic (tonicity and following context) and extra-linguistic (age, education, sex, mobility and localism) factors were analyzed. or not about the variants described. For the development of the research, part of the data collected by Martins (2013) was used for his doctoral thesis. The corpus used was composed of 12 informants, stratified according to age, sex and education. In total, there were 3.888 /S/ realizations in syllabic coda. The analyzed data showed that the alveopalatal variant $(66,3 \%)$ was the most performed by Tonantinenses, in addition to showing the independent linguistic and extralinguistic variables that favored the use of this variant, respectively: following context, sex, mobility, age and occupation.

Key words: Variation; /S/; coda; Tonantins (AM).

\footnotetext{
1 Professora adjunta na Faculdade de Letras da Universidade Federal do Amazonas (UFAM). Doutora em Linguística. E-mail: flavinhaingrid@yahoo.com.br

2 Graduanda do Curso de Letras-Língua e Literatura Portuguesa, Universidade Federal do Amazonas, Faculdade de Letras. Email: vanessalarasantoss@gmail.com
} 


\section{Introdução}

Nesta pesquisa, estudou-se o fenômeno variável /S/ em coda silábica no falar dos moradores da cidade de Tonantins, no Amazonas ${ }^{3}$. Para tanto, utilizou-se como arcabouço teórico da Sociolinguística Variacionista (LABOV, 2008 [1972]; WEINREICH, LABOV e HERZOG, 2006 [1968]; COELHO et. al., 2015; BRAGA e MOLLICA, 2015), assim como outros estudos sobre o referido fenômeno já realizados no Brasil (SILVA NETO, 1960; SCHERRE e MACEDO, 1991; CANOVAS, 1991; CALLOU e MORAES, 1996; HORA, 2000; A. MARTINS, 2001; BRESCANCINI, 2002; JESUS e MOTA, 2006; SMAICLOVÁ, 2010; BASSI, 2011, dentre outros) a fim de postular hipóteses e controlar variáveis independentes linguísticas e extralinguísticas.

Segundo os estudos a respeito do fenômeno, o arquifonema $/ \mathrm{S} /{ }^{4}$ se realiza por meio das seguintes variantes: i) a alveolar surda e sonora [s, z]; ii) a alveopalatal surda e sonora [ 0 , 3]); iii) a fricativa glotal surda e sonora [h, t] e iv) o apagamento [ø]. Além de descrever as variantes do referido fenômeno, esses estudos evidenciam que essa variação não é aleatória, pois mostram que existem variáveis independentes condicionando o uso de uma ou outra variante, tanto linguísticas quanto extralinguísticas.

Dessa forma, o estudo em questão teve como objetivos específicos: i) descrever as variantes da variável dependente /S/ em coda silábica existentes no falar dos moradores da cidade de Tonantins (Amazonas); ii) analisar as variáveis independentes, linguísticas e extralinguísticas, que influenciam o uso de uma ou outra variante do /S/ em coda silábica no falar dos moradores da cidade de Tonantins (Amazonas). No que tange às variáveis linguísticas, foram controladas ${ }^{5}$ tonicidade, contexto seguinte e posição. No que se refere às variáveis extralinguísticas, foram controladas escolaridade, sexo, idade e redes sociais (mobilidade e localismo).

Vale lembrar que, para este estudo, o corpus foi retirado de parte dos dados coletado por F. Martins (2013) para sua tese de doutoramento ${ }^{6}$. Destaca-se que a referida pesquisadora investigou um fenômeno morfossintático a "concordância nominal de número". Nesta pesquisa, no entanto, investigamos um fenômeno fonético-fonológico, ampliando, assim, o estudo desse corpus já constituído.

O corpus se constituiu de 12 informantes, conforme a estratificação em idade (18 a 35 anos, 36 a 55 anos, mais de 56 anos), sexo (homem e mulher) e escolaridade (4 a 8 anos de escolarização e

\footnotetext{
3 Este artigo é resultado de um trabalho de Iniciação Científica realizado na Universidade Federal do Amazonas no período de 2018/02 a 2019/01 sob a inscrição PIB-LLA-001-2018.

4 Vale lembrar como acontece a variação posicional das variantes alveopalatal surda e sonora e alveolar surda e sonora no PB: de acordo com Silva (2003, p. 145), "o alofone posicional [s] ou [S] ocorre em posição posvocálica seguido de consoante desvozeada", enquanto o "alofone posicional [z] ou [Z] ocorre em posição posvocálica seguido de consoante vozeada". Nesta pesquisa, consideramos os alofones [s] e [z], assim como [S] e [Z] amalgamados (variantes alveolares e alveopalatares, respectivamente) cientes da referida variação posicional em função da assimilação do traço de sonoridade da consoante seguinte.

5 Em uma pesquisa sociolinguística, sabemos que a variação não ocorre de forma aleatória, por trás dela há condicionadores motivando a escolha de uma ou outra variante. Para compreendermos quais são esses condicionadores, fazemos o controle de variáveis independentes (linguísticas e extralinguísticas), considerando as que se têm mostrado relevantes em outras pesquisas já realizadas sobre o mesmo fenômeno. A partir desse controle de variáveis independentes, o programa estatístico, no caso o GoldvarbX, seleciona quais delas tem um peso maior sobre o fenômeno em investigação (cf. GUY e ZILLES, 2007).

6 Nesse estudo, a referida pesquisadora investigou cinco municípios pertencentes à microrregião do alto Solimões com o intuito de ampliar o número de municípios estudados por Cruz (2004): Fonte Boa, Jutaí, Santo Antônio do Içá, São Paulo de Olivença e Tonantins. Quanto à quantidade de informantes entrevistados por F. Martins (2013), no total, foram 57, totalizando “12" por localidade (algumas células, no entanto, ficaram incompletas, uma vez que não se conseguiu em Fonte Boa e Jutaí alguns informantes no perfil traçado pela pesquisadora).

7 Neste artigo assumimos essa terminologia, tendo em vista que na coleta de dados, temos considerado o sexo do informante e não o gênero (embora a discussão feita na análise se paute no gênero e não no sexo),
} 
9 a 11 anos de escolarização). A fim de entendermos quais grupos de fatores, linguísticos e extralinguísticos, influenciam o uso de uma ou outra variante, controlamos, nesta pesquisa, os seguintes: posição (medial e final), tonicidade (pretônica, tônica e postônica), contexto seguinte (consoante, vogal e pausa), sexo (homem e mulher), idade (18 a 35 anos, 36 a 55 anos, mais de 56 anos), escolaridade (4 a 8 anos de escolarização e 9 a 11 anos de escolarização), ocupação (alta, média e baixa), mobilidade (pouca, média e muita) e localismo (pouco integrado, mais ou menos integrado, mais integrado).

Dado o exposto, este artigo foi organizado da seguinte forma: i) O /S/ em coda silábica no Brasil; ii) Análise estatística e discussão dos dados e, por fim, as considerações finais.

\section{O /S/ em coda silábica no Brasil}

Como exposto na Introdução, no Português Brasileiro (PB, doravante), o /S/ em coda silábica constitui um fenômeno variável e já foi investigado por diversos pesquisadores que atestam a sistematicidade dessa variação. Com o intuito de ilustrar alguns dos trabalhos realizados no Brasil, cronologicamente, segue o Quadro 1:

Quadro 1- Alguns estudos sobre o /S/ em coda silábica no Brasil

\begin{tabular}{|l|l|l|}
\hline Ano & Autor(es) & Informações sobre o estudo \\
\hline 1960 & Silva Neto & $\begin{array}{l}\text { Estudou o problema do sistema das sibilantes na língua portuguesa no que diz } \\
\text { respeito ao consonantismo. }\end{array}$ \\
\hline 1991 & Scherre e Macedo & Investigaram o falar carioca. \\
\hline 1991 & Canovas & Estudou a fala dos moradores de Salvador (Bahia). \\
\hline 1996 & Callou e Moraes & $\begin{array}{l}\text { Pesquisaram dados de fala de cinco capitais que fazem parte do corpus do projeto } \\
\text { Norma Urbana Culta (NURC): Salvador, Recife, Porto Alegre, Rio de Janeiro e } \\
\text { São Paulo. }\end{array}$ \\
\hline 2000 & Hora & Estudou as fricativas coronais no falar paraibano. \\
\hline 2001 & A. Martins & Investigou a fala dos habitantes de Bragança (PA). \\
\hline 2002 & Brescancini & Estudou a fala dos moradores de Florianópolis (SC). \\
\hline 2006 & Jesus e Mota & $\begin{array}{l}\text { Pesquisaram a fala de Salvador (BA) e Recife (PE) a partir dos dados do Atlas } \\
\text { Linguístico do Brasil (doravante AliB). }\end{array}$ \\
\hline 2010 & Smaiclová & $\begin{array}{l}\text { Trabalhou a palatalização do / S/ em coda silábica na fala dos residentes da Costa } \\
\text { da Lagoa, em Florianópolis. }\end{array}$ \\
\hline 2011 & Bassi & $\begin{array}{l}\text { A partir do corpus do ALiB, comparou a fala dos habitantes do Rio de Janeiro e } \\
\text { Florianópolis. }\end{array}$ \\
\hline
\end{tabular}

Fonte: autoria própria (adaptado do Relatório Final "Variação do /S/ em coda silábica no falar dos moradores da cidade de Tonantins (Amazonas)”, realizado em 2018/2019).

No que se refere aos trabalhos discriminados anteriormente, realizaremos uma discussão breve a respeito de dois estudos mais recentes sobre o fenômeno em estudo a fim de compreendêlo melhor. São eles: Smaiclová (2010) e Bassi (2011).

Smaiclová (2010) investigou a palatalização do /S / em coda silábica na fala dos moradores da Costa da Lagoa, em Florianópolis (SC). Para tanto, analisou os dados coletados pelo VARSUL (Variação Linguística Urbana na Região Sul do Brasil) e os dados coletados pela própria pesquisadora entre junho e julho de 2009. No total, foram 8 entrevistas, sendo 5 coletadas por Smaiclová e 3 do projeto VARSUL. Consideraram-se as seguintes variantes para o referido estudo: "alveolares surda e sonora [s,z]" e "alveopalatais surda e sonora [f, 3]". Smaiclová (2010) baseou-se no estudo de Brescancini (1996) para formular as hipóteses iniciais a respeito das variáveis independentes linguísticas e extralinguísticas tais quais: traço de sonoridade da consoante seguinte, tonicidade, tipo de item lexical, contexto precedente, contexto seguinte, escolaridade (nivel primário completo ou incompleto e nivel superior) e idade (15-25, 26-50, mais de 50).

De acordo com Brescancini (1996 apud Smaiclová, 2010), o fenômeno da palatalização é

cf. Freitag (2015).

https://periodicos.unifap.br/index.php/letras

Macapá, v. 10, n. 1, $1^{\circ}$ sem., 2020 
mais condicionado por consoante surda, por contextos tônicos e pré-tônicos anteriores, por numerais, por contexto precedente formado por vogais dorsais, por contexto seguinte formado por consoantes dorsais, embora a variável contexto seguinte não tenha sido considerada tão significativa no estudo. A respeito das variáveis sociais, a hipótese era de que o fenômeno referido acontecesse mais entre os indivíduos com nível primário completo ou incompleto e entre os mais jovens (15-25).

Os resultados de Smaiclová (2010) mostraram que a realização da alveopalatal (77\%) se sobrepôs à realização da alveolar $(23 \%)$ na comunidade da Costa da Lagoa. Os condicionadores que mais influenciaram na escolha da variante "palatal" foram: i) contexto seguinte; ii) idade; iii) escolaridade e iv) vozeamento (nessa ordem de seleção). Smaiclová (2010) percebeu que, diferentemente do resultado de Brescancini (1996), o contexto seguinte foi o condicionador mais favorecedor para a realização da referida variante. O contexto seguinte mais favorecedor para o uso da "palatal" foi o contexto dorsal $(0,69)$, seguido das coronais $(0,62)$. No que se refere à idade, mais uma vez, os resultados não estão de acordo com a formulação de Brescancini (1996), uma vez que os falantes da faixa etária superior aos 50 anos palatalizam mais $(0,86)$, enquanto os mais jovens $(15-25)$ a desfavorecem $(0,43)$. No que tange à escolaridade, os falantes com nível superior favorecem a "palatal" $(0,60,75 \%)$, já os com nível primário $(0,43,75 \%)^{8}$ a desfavorecem. Por fim, a respeito do vozeamento, a hipótese inicial foi comprovada, já que as consoantes surdas são as que mais favorecem o fenômeno da palatalização $(0,55)$, enquanto os fatores žro e consoantes sonoras desfavorecem a realização da variante, 0,43 e 0,31, respectivamente.

Bassi (2011), por sua vez, estudou o /S/ pós-vocálico nas cidades do Rio de Janeiro e de Florianópolis, por meio dos dados extraídos do projeto ALiB (Atlas Linguístico do Brasil). O corpus, então, foi constituído de 8 informantes, para cada capital, distribuídos em faixa etária (18-30, 5065), sexo (homem, mulher) e escolaridade (formação até a $7^{\mathrm{a}}$ série do ensino fundamental) e, ainda, ter profissão definida e não apresentar muita mobilidade. Para essa pesquisa, consideraram-se as variantes "alveolar", "alveopalatal" e "zero fonético". A autora controlou os seguintes grupos de fatores: sexo, escolaridade, idade, dimensão diafásica, localidade, posicão, tonicidade, contexto precedente, contexto seguinte, vozeamento e número de sílabas. Por meio da submissão dos dados ao programa de análise estatística Goldvarb, versão 2.0, os resultados mostraram que a "alveopalatal" foi mais utilizada no Rio de Janeiro, com 87,8\%, do que em Florianópolis, 65,3\%. Além disso, os condicionadores linguísticos foram os que mais favoreceram o fenômeno da palatalização, entre eles estão: posição medial, tonicidade, contexto precedente formado por vogais coronais, entre outros. No que tange aos condicionadores extralinguísticos, favorecem o fenômeno da palatalização a variável dimensão diafásica- resposta aos questionários, no Rio de Janeiro, e a conversação livre, em Florianópolis.

No que se refere a estudos realizados, especificamente, no Amazonas, desde 2004, com a elaboração do Atlas Linguístico do Amazonas (doravante ALAM) por Cruz como tese de doutoramento, a investigação sobre variação linguística na referida região tem sido objeto de estudo, mas ainda há muito o que se fazer.

Cruz (2004), em sua tese, investigou 9 municípios, cada um representando uma microrregião 9 distinta: Barcelos (Microrregião do Alto Rio Negro), Benjamin Constant (microrregião do Alto Solimões), Eirunepé (microrregião do Juruá), Humaitá (microrregião do Madeira), Itacoatiara (Microrregião do Médio Amazonas), Lábrea (microrregião do Purus), Manacapuru (microrregião do Rio Negro-Solimões), Parintins (microrregião do Baixo Amazonas) e Tefé (microrregião do JutaíSolimões-Juruá).

Quanto ao fenômeno aqui em discussão, Cruz (2004) chegou ao seguinte resultado: o de que pode haver áreas linguísticas diferenciadas no Amazonas, uma vez que existem aspectos linguísticos diferenciados entre os falares dos informantes entrevistados nas microrregiões do Rio Negro, Ama-

\footnotetext{
8 Os resultados percentuais, por sua vez, confirmam a hipótese inicial.

9 Cruz (2004) utilizou a divisão em microrregiões que consta na Constituição de 1988. Nos dados do IBGE 2010, há uma divisão diferente dessas microrregiões.
} 
zonas e Solimões. Na microrregião dos Rios Negro e Amazonas, há o uso com maior frequência da variante "alveopalatal surda e sonora", já na microrregião do Rio Solimões, o predomínio é da variante "alveolar surda e sonora".

Esse resultado levou à realização de alguns estudos no Amazonas sobre esse mesmo fenômeno (monografias, relatórios de iniciação científica e dissertações) a fim de atestar ou não a hipótese levantada por Cruz (2004) de haver áreas linguísticas diferenciadas a respeito do /S/ em coda silábica. Podemos citar os trabalhos de iniciação científica de: i) F. Martins (2006/2007) que realizou um estudo sobre a fala dos moradores de Benjamin Constant, Itacoatiara, Manacapuru, Barcelos, Parintins e Tefé, a partir dos dados de conversação livre do ALAM ${ }^{10}$; ii) Quara (2007) que investigou os dados de fala dos habitantes de Humaitá, Lábrea e Eirunepé, também a partir dos dados de conversação livre do ALAM ${ }^{11}$. Também podemos mencionar os trabalhos resultantes de pesquisa de mestrado: i) Brito (2011) elaborou o Atlas dos Falares do Baixo Amazonas; ii) Justiniano (2012) elaborou o Atlas Linguístico dos Falares do Alto Rio Negro; E. Maia (2012) pesquisou a fala dos habitantes do município de Boca do Acre, Lábrea e Tapauá, dentre outros.

F. Martins (2007/2008) investigou o /S/ em coda silábica nos municípios de Itacoatiara, Manacapuru, Parintins, Tefé, Barcelos e Benjamim Constant a partir dos dados de conversação livre extraídos do corpus do ALAM. Os resultados da pesquisa, de maneira geral, comprovam a hipótese de Cruz (2004) a respeito da distinção entre as áreas dialetais referentes às regiões dos rios Negro, Amazonas e Solimões. Embora tenha sido analisada a conversação livre, o resultado mostrou a mesma distribuição das variantes que foi encontrada na investigação da resposta aos questionários feita por Cruz (2004). Portanto, de um lado a pronúncia dos municípios de Barcelos, Itacoatiara e Parintins (Rios Negro e Amazonas) foi caracterizada pelo uso da "alveopalatal". De outro, em Tefé, Benjamim Constant e Manacapuru (Alto Solimões) é predominantemente o uso da variante "alveolar".

Brito (2011) elaborou o Atlas dos Falares do Baixo Amazonas (AFBAM). Para tanto, aplicou o mesmo questionário utilizado por Cruz (2004) para a elaboração do ALAM. A pesquisadora investigou os seguintes municípios: Barreirinha, Boa Vista do Ramos, Nhamundá, São Sebastião do Uatumã e Urucará. Foram selecionados 6 informantes por município, sendo 1 homem e 1 mulher, distribuídos em três faixas etárias. Os resultados desse estudo constataram a hipótese de Cruz (2004) sobre a distinção das áreas dialetais dos Rios Negro e Amazonas e Rio Solimões. Dessa forma, a variante "alveopalatal" foi a predominante nos municípios estudados (o mesmo resultado que Cruz, 2004, encontrou em Parintins, representante da microrregião do Baixo Amazonas).

Justiniano (2012) elaborou o Atlas Linguístico dos Falares do Alto Rio Negro (ALFARIN). Baseando-se na metodologia de Cruz (2004), a referida pesquisadora investigou 3 municípios: Santa Isabel do Rio Negro, São Gabriel da Cachoeira e Barcelos. A variante "alveopalatal” foi a predominante nos municípios referidos, embora no município de Santa Isabel do Rio Negro tenha aparecido a "alveolar" realizada somente pelos homens mais jovens. Resultado que também atestou a hipótese de Cruz (2004) $)^{12}$.

Martins e Margotti (2012) investigaram o comportamento fonético-fonológico do /S/ pósvocálico, tanto em posição de coda medial quanto em posição de coda final, na fala manauara, por meio dos dados coletados para o ALiB. A pesquisa segue os pressupostos teórico-metodológicos da Dialetologia Pluridimensional. As variantes investigadas foram: a "alveolar surda e sonora", a "alveopalatal surda e sonora" e a "glotal surda e sonora". No geral, foram analisados 641 dados fonéticos, sendo 355 em posição medial e 286 em posição final. As variáveis independentes controladas foram: sexo (homem, mulher), idade (18-30, 45-60) e escolaridade (nível primário e nível su-

\footnotetext{
10 Ressalta-se que Cruz (2004) coletou dados através de questionários objetivos, assim como dados de conversação livre. Em sua pesquisa, porém, somente utilizou os dados resultantes dos questionários objetivos, seguindo, portanto, o método por excelência da Dialetologia Pluridimensional, a Geolinguística.

11 Não encontramos o referido trabalho disponível para consulta.

12 Vale ressaltar que Brito (2011) e Justiniano (2012) apresentam poucas informações sobre o fenômeno em questão, já que o trabalho delas se refere a um Atlas Linguístico.
} 
perior, completos ou não) ${ }^{13}$.

Os referidos autores concluíram que, em posição medial, houve uma distribuição homogênea das variantes "alveolar" (50,1\%) e "alveopalatal" (47\%). Já, em posição final, a variante "alveolar" se sobrepôs à variante "alveopalatal" com $67,1 \%$ e 32,8\%, respectivamente. No que diz respeito às variáveis extralinguísticas, acerca do sexo, observaram, em posição medial, que os homens realizaram mais a "alveolar" (68\%), enquanto as mulheres usaram mais a "alveopalatal" (69\%) e, ainda, houve uma distribuição equilibrada a respeito da realização da "aspirada" entre homens e mulheres (3,1\% e 2,4\%, respectivamente). Em posição final, as mulheres também usam com mais frequência a "alveopalatal" (63\%). Vale lembrar que a "predileção" das mulheres pelo uso da variante "alveopalatal" é um indicativo de que essa variante seja a mais prestigiada, pois as mulheres, do ocidente, "lideram a mudança quando essas são consideradas de prestígio" (PAIVA IN MOLLICA e BRAGA, 2008, p. 268). Sobre a idade, os dados mostram que os mais jovens usam mais a variante "alveopalatal" (38,2\%), em posição final. Por fim, a respeito da escolaridade, nas posições medial e final, os informantes com nivel superior usaram mais a "alveopalatal", comparados com os de nivel fundamental.

No intuito de ampliar a investigação sobre o /S / em coda silábica feita por Cruz (2004), E. Maia (2012) pesquisou esse fenômeno linguístico na microrregião do Purus, que ainda não tinha sido estudada em âmbito linguístico (exceto o município de Lábrea que já havia sido estudado pelo ALAM), que abrange os municípios de Lábrea, Canutama, Tapauá, Pauini e Boca do Acre. Todavia, o pesquisador se focou em três desses municípios: Boca do Acre, Lábrea e Tapauá. A pesquisa é de cunho dialetológico pluridimensional e se utilizou das Teorias do Traço Distintivo e da sílaba para explicar a "predileção" por algumas variantes em determinados contextos fonético-fonológicos. A respeito do corpus, foram selecionados 18 informantes, sendo 6 por município (1 homem e 1 mulher, distribuídos em três faixas etárias: 18-38, 36-55, mais de 56). As perguntas feitas pelo pesquisador direcionavam o entrevistado a uma resposta objetiva (metodologia da Geolinguística).

As variantes estudadas por E. Maia ${ }^{14}$ (2012) foram: "alveolar surda e sonora", "alveopalatal surda e sonora", "glotal surda e sonora" e "zero fonético". A primeira variante mencionada foi a mais usada, no geral. Com isso, o pesquisador confirmou a hipótese formulada por Cruz (2004) de que haveria uma divisão dialetal no Estado do Amazonas: enquanto nas regiões próximas aos Rios Negro e Amazonas há uma predominância da pronúncia "alveopalatal", nas regiões do Rio Solimões, a predominância é da pronúncia "alveolar". Já que a Microrregião do Purus é próxima do Rio Solimões, a "alveolar", de fato, seria a mais realizada entre os falantes. A respeito dos contextos que favorecem o uso das variantes estudadas, E. Maia (2012) concluiu: i) A “alveopalatal" é favorecida por contexto medial anterior à oclusiva /t/. Isso pode ser explicado pela Teoria dos Traços Distintivos, segundo a qual o $[\mathrm{t}]$ possui um traço comum ao $[\mathrm{s}]$, o traço [+coronal]; ii) a "alveolar" é favorecida pelo contexto medial anterior às fricativas $[\mathrm{f}, \mathrm{v}]$ e às oclusivas $[\mathrm{p}, \mathrm{k}]$; iii) a "glotal" é favorecida pelo contexto medial anterior à lateral / $/$ e e $/ \mathrm{t} \int /$ e iv) o "apagamento" é condicionado pelo contexto final como morfema de plural.

Como se observa, já há alguns estudos no Amazonas no que diz respeito ao /S/ em coda silábica, mas ainda existem várias cidades a serem investigadas, como é o caso de Tonantins, pertencente à microrregião do Alto Solimões. Vale ressaltar que Cruz (2004) apenas investigou a cidade de Benjamin Constant como representante da referida microrregião. Nesta pesquisa, pretendeu-se, enfim, ampliar o estudo dessa região a partir do registro sistematizado do fenômeno em foco. É importante destacar ainda que essa microrregião já vem sendo estudada a respeito desse mesmo fenômeno em outros trabalhos de iniciação científica: i) $O$ aluno Richardson Borges Maia (2015/2016) investigou o município de São Paulo de Olivença; ii) A aluna Keren Barbosa de Melo (2017/2018) estudou o município de Jutaí e iii) Há um trabalho em andamento da aluna Ana Ca-

\footnotetext{
13 Não foi utilizado programa estatístico para controle de variáveis independentes, por isso os resultados apresentam-se apenas em percentuais.

14 Também não utilizou programa estatístico.
} 
rolina de Melo Cavalcante do Vale sobre o fenômeno variável /S/ em coda silábica (2019/2020) na cidade de Fonte Boa (AM). Os três estudos utilizaram o corpus coletado por F. Martins (2013), também utilizado nesta pesquisa.

Ao investigar o município de São Paulo de Olivença, R. Maia (2015/2016) apontou que a variante "alveopalatal surda e sonora" foi a variante realizada com mais frequência pelos informantes, com $67,5 \%$, seguida das variantes "alveolar surda e sonora" $(25,7 \%)$, "glotal surda e sonora" (6,1\%) e "apagamento" (0,7\%). As variáveis independentes controladas foram: idade, sexo, escolaridade, contexto seguinte, posição, tonicidade, ocupação, mobilidade e localismo. Dessas variáveis controladas, o programa de análise estatística GoldVarbX selecionou como atuantes para a aplicação da regra as seguintes, nessa ordem de seleção: contexto seguinte, tonicidade, ocupação, localismo, sexo e posição. O programa, portanto, não selecionou as variáveis idade, mobilidade e escolaridade. R. Maia (2015/2016), concluiu, de acordo com os resultados, a respeito dos condicionadores linguísticos, que a variante mais realizada, a "alveopalatal surda e sonora", é favorecida pelo contexto seguinte, quando este é consoante; pela tonicidade, quando a sílaba é pré-tônica; e pela posição, quando é final da palavra. A respeito dos condicionadores extralinguísticos, a "alveopalatal surda e sonora" é favorecida pela ocupação (mercado de trabalho), especificamente pelo fator cotação baix ${ }^{15}$, como donas de casa e aposentados; pelo localismo, especialmente pelos habitantes bem integrados, ou seja, aqueles que possuem um sentimento de pertencimento ao município; e pelo sexo, os homens utilizam mais a referida variante. Os resultados, no geral, não estão de acordo com a hipótese de Cruz (2014), uma vez que o município em questão pertence à microrregião do Alto Solimões e nessa, segundo Cruz (2014), a predominância seria da variante "alveolar surda e sonora" e não da "alveopalatal surda e sonora", como constatou R. Maia (2015/2016).

Ao estudar a cidade de Jutaí, Melo (2017/2018), por sua vez, mostrou que a variante mais utilizada pelos moradores do município é a "alveolar surda e sonora" (43,4\%), seguida das variantes "alveopalatal surda e sonora" (41,4\%), "glotal surda e sonora" (10,8\%) e "apagamento" (4,6\%). Nesse estudo, foram controladas as seguintes variáveis independentes: posição, tonicidade, contexto seguinte, escolaridade, idade, sexo, mobilidade, localismo e ocupação. Os dados foram submetidos ao programa de análise estatística GoldVarbX e, assim, foram selecionadas ${ }^{16}$ como relevantes, por ordem de seleção, os grupos de fatores que seguem: contexto seguinte, idade, sexo e escolaridade. Os resultados mostraram que a variante "alveolar surda e sonora", considerada como aplicação da regra, é mais condicionada não só quando o contexto seguinte é vogal, mas também quando os informantes têm o seguinte perfil: são mais velhos, menos escolarizados e homens. Os resultados desse estudo, portanto, estão de acordo com os resultados de Cruz (2014), já que Jutaí pertence à microrregião do Alto Solimões e a variante mais utilizada, de fato, foi a "alveolar surda e sonora".

\section{Análise estatística e discussão dos resultados}

Apresentaremos, nesta seção, os resultados encontrados para a realização do /S/ em coda silábica na fala dos informantes entrevistados no município de Tonantins (AM). Para a análise estatística dos dados, utilizou-se o programa GoldVarbX. Vale lembrar, entretanto, que, durante a categorização dos áudios, dados de assimilação foram excluídos, como por exemplo: i) dois rapaz

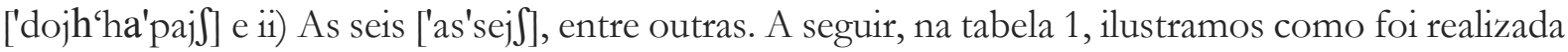
a transcrição fonética do corpus:

\footnotetext{
${ }^{15}$ Cotação baixa: informantes que ocupam cargos que não exigem tanto o uso da norma "padrão".

${ }^{16}$ As variáveis localismo, mobilidade e ocupação foram excluídas da rodada estatística. A primeira foi excluída pelo fato de todos informantes se mostrarem bem integrados à "comunidade de fala", acontecendo na rodada o que se chama de knockout. Sobre as variáveis mobilidade e ocupação, a mobilidade se sobrepôs a variável contexto seguinte enquanto a variável ocupação se sobrepôs à variável idade.
} 
Tabela 1- Informante 003BM ${ }^{17}$ (Tonantins-AM)

\begin{tabular}{|c|c|c|c|}
\hline $\mathbf{N}^{\mathbf{0}}$ & TEMPO & PALAVRA & TRANSCRIÇÃO \\
\hline 01 & $00: 09$ & Cristal & [krI']'taw] \\
\hline 02 & $00: 28$ & Anos... & ['Mnus]... \\
\hline 03 & $00: 30$ & Anos... & ['Mnus]... \\
\hline 04 & $00: 32$ & Escola & [Is'kole] \\
\hline
\end{tabular}

Fonte: autoria própria.

No geral, transcreveu-se um total de 3.888 realizações do /S/ em coda silábica, em posição medial e em posição final ${ }^{18}$. Os resultados mostraram que a variante mais utilizada foi a "alveopalatal", com 66,3\% (2.579 dados), seguida das variantes "alveolar", com 25,7\% (998 dados); "glotal", com 7,7\% (299 dados) e o "zero fonético", com 0,3\% (12 dados). No Gráfico 1, a seguir, ilustramos a distribuição das quatro variantes encontradas no falar de Tonantins (AM):

\section{Gráfico 1- Distribuição do /S/ em coda silábica no município de Tonantins (AM)}

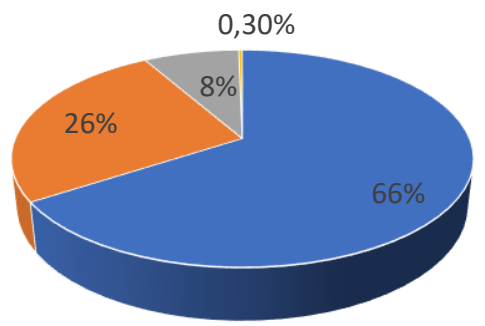

- Alveopalatal

- Alveolar

- Glotal

Zero fonético

Fonte: autoria própria (adaptado do Relatório Final "Variação do /S/ em coda silábica no falar dos moradores da cidade de Tonantins (Amazonas)", realizado em 2018/2019).

Nesta pesquisa, controlaram-se as seguintes variáveis independentes linguísticas: posição, tonicidade e contexto seguinte. A respeito das variáveis independentes extralinguísticas, controlaram-se: escolaridade, idade, sexo, mobilidade, localismo e ocupação. Durante a realização da rodada estatística, foram excluídas as variáveis posição, tonicidade e localismo. A primeira foi excluída por se sobrepor à variável contexto seguinte; a segunda por se sobrepor também à variável contexto seguinte; e a última por se sobrepor à escolaridade e à idade. Ademais, pelo fato de knockout na variável contexto seguinte no que se refere ao [1], foi necessário amalgamar as consoantes laterais $[1, \Lambda]$.

Feitas as exclusões das variáveis referidas, o programa de análise estatística GoldVarbX mostrou a atuação das seguintes variáveis independentes linguísticas e extralinguísticas sobre a aplicação da regra", a variante "alveopalatal surda e sonora", por ordem de seleção: contexto seguinte, sexo, mobilidade, idade e ocupação. A seguir, apresentaremos, em duas subseções, a análise descritiva das variáveis independentes linguísticas e extralinguísticas.

\subsection{As variáveis independentes linguísticas}

A respeito das variáveis independentes linguísticas, discutiremos sobre a influência da variável contexto seguinte no uso da variante "alveopalatal surda e sonora". Vale ressaltar que essa variável foi a única variável linguística discutida nesta pesquisa, uma vez que as outras variáveis linguísticas

17 Para 001, lê-se $1^{a}$ faixa etária; para 002, $2^{a}$ faixa etária e para 003, 3ª faixa etária. Para A, lê-se menos escolarizado e para B, mais escolarizado. Para M, lê-se homem e para F, mulher.

18 Para acesso a todos esses dados transcritos, podem nos solicitar por email.

$19 \mathrm{Na}$ análise estatística dos dados, foi considerada como aplicação da regra a variante "alveopalatal surda e sonora". Os outros dados devem ser lidos como o conjunto das variantes "alveolar surda e sonora, a glotal surda e sonora e o zero fonético". 
posição e tonicidade foram excluídas na rodada estatística feita, conforme já explicitado.

O contexto seguinte foi a variável que mais favoreceu a realização da variante "alveopalatal surda e sonora". Podemos dizer que a realização dessa variante foi mais favorecida, sobretudo, pelos seguintes contextos: i) /S/ seguido de consoante e ii) Pausa. A seguir, na Tabela 2, mostramos a realização da variante referida em relação à variável contexto seguinte:

Tabela 2- Frequência e probabilidade da variante "alveopalatal surda e sonora", segundo a variável contexto seguinte

\begin{tabular}{|c|c|c|c|c|}
\hline \multicolumn{2}{|r|}{ Fatores } & Aplicação/ Total & $\%$ & P.R \\
\hline \multirow{14}{*}{ Consoante } & [t] Ex. (Inf.003BM): [kriJ'taw] & $751 / 794$ & $94,6 \%$ & 0,91 \\
\hline & [d3] Ex. (Inf.003BF): ['majzdzI'pojf] & $87 / 97$ & $89,7 \%$ & 0,82 \\
\hline & 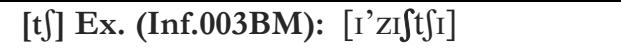 & $73 / 85$ & $85,9 \%$ & 0,79 \\
\hline & 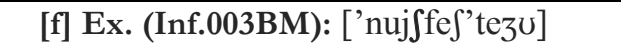 & $117 / 138$ & $84,4 \%$ & 0,76 \\
\hline & [g] Ex. (Inf.003BF): ['doj3'grupu] & $14 / 17$ & $82,4 \%$ & 0,74 \\
\hline & [p] Ex. (Inf.003BM): [hes'pejtu] & $213 / 262$ & $81,3 \%$ & 0,74 \\
\hline & [d] Ex. (Inf.003AM): ['dew3'du] & $68 / 87$ & $78,2 \%$ & 0,68 \\
\hline & [k] Ex. (Inf.003BM): [d3IS'kawsu] & $416 / 558$ & $74,6 \%$ & 0,63 \\
\hline & [b] Ex. (Inf.003AM): ['uz'bifu] & $37 / 51$ & $72,5 \%$ & 0,63 \\
\hline & [n] Ex. (Inf.003BF): ['maj3'nuj3] & $93 / 140$ & $66,4 \%$ & 0,53 \\
\hline & [h] Ex. (Inf.003AF): ['varıw She'medziw] & $6 / 8$ & $75 \%$ & 0,52 \\
\hline & [v] Ex. (Inf.003BF): ['mujte3'veziz] & $59 / 89$ & $66,3 \%$ & 0,51 \\
\hline & [1, $\left.{ }_{0}\right]$ Ex. (Inf.003AM): ['mez'la] & $9 / 18$ & $50 \%$ & 0,36 \\
\hline & [m] Ex. (Inf.003BF): ['mezmu] & $151 / 417$ & $36,2 \%$ & 0,24 \\
\hline \multicolumn{2}{|r|}{ Pausa: Ex. (Inf.003BF): ['maj J]... } & $482 / 605$ & $79,7 \%$ & 0,71 \\
\hline \multicolumn{2}{|r|}{ Vogal: Ex. (Inf.003AF): ['okvlujf][a’de] } & $3 / 520$ & $0,6 \%$ & 0,02 \\
\hline $\begin{array}{l}\text { Signif } \\
\text { Input. }\end{array}$ & cia: 0,000 & & & \\
\hline
\end{tabular}

Fonte: autoria própria (adaptado do Relatório Final "Variação do /S/ em coda silábica no falar dos moradores da cidade de Tonantins (Amazonas)", realizado em 2018/2019).

Verificamos que a variante "alveopalatal surda e sonora" é favorecida pela consoante [t] $(0,91)$, seguida das consoantes [d 3$](0,82),[\mathrm{t}](0,79),[\mathrm{f}](0,76),[\mathrm{g}](0,74),[\mathrm{p}](0,74)$ e pelo contexto pausa $(0,71)$. Observamos que, das consoantes mencionadas, as que mais favoreceram a aplicação da regra são, em sua maioria, surdas. Percebemos também que as consoantes que favorecem a aplicação da regra apresentam um outro traço articulatório em comum: o modo de articulação. Por exemplo, os seguintes sons [t, p, g, d, k, b] são todos oclusivos. Ainda, percebe-se que as consoantes com o modo de articulação denominado africado também favorecem o uso da variante "alveopalatal surda e sonora": [t $]$ e [dz].

A respeito dos contextos seguintes desfavoráveis à aplicação da regra, temos as consoantes $[1, K$, $\mathrm{m}]$ e as vogais. Sobre a consoante [m], é importante ressaltar que, durante a transcrição dos dados, percebeu-se que essa consoante parece favorecer o uso da variante "glotal", como, por exemplo, na palavra "mesmo" ['mefimu]. As laterais $[1, K]$, por sua vez, também não favorecem a realização da variante "alveopalatal". Também, essas duas consoantes parecem favorecer a variante "glotal", como em "mais legal”: ['majflic'gaw]. Vale salientar que as três consoantes que desfavoreceram a aplicação da regra $[1, K, \mathrm{~m}]$ apresentam como traço articulatório em comum serem [+soantes].

Sobre as vogais, observamos que são as que menos favorecem a aplicação da regra. Isso porque as vogais parecem favorecer o uso da variante alveolar "surda e sonora" [s, z], assim como o uso da "glotal", como em "mas eu": ['majzew], ['majhew], em função do padrão silábico. 


\subsection{Os grupos de fatores extralinguísticos}

As variáveis independentes extralinguísticas que mais favoreceram o uso da variante "alveopalatal surda e sonora" foram, por ordem de seleção: sexo, mobilidade, idade e ocupação. É importante destacar que o grupo de fatores escolaridade não foi selecionado.

Em relação à variável sexo, esta foi a variável extralinguística mais relevante no que se refere à aplicação da regra, sendo selecionada em segundo lugar na rodada estatística. $\mathrm{Na}$ Tabela 3, a seguir, verificamos os resultados:

Tabela 3- Frequência e probabilidade da variante "alveopalatal surda e sonora", segundo a variável sexo

\begin{tabular}{l|l|c|c}
\hline \multicolumn{1}{c|}{ Fatores } & \multicolumn{1}{c|}{ Aplicação/ Total } & \% & P.R \\
\hline Mulher & $1390 / 1883$ & $73,8 \%$ & 0,61 \\
\hline Homem & $1189 / 2003$ & $59,4 \%$ & 0,38 \\
\hline
\end{tabular}

Significância: 0,000

Input: 0,65

Fonte: autoria própria (adaptado do Relatório Final "Variação do /S/ em coda silábica no falar dos moradores da cidade de Tonantins (Amazonas)", realizado em 2018/2019).

Verifica-se, na Tabela 3, que as mulheres $(0,61)$ favorecem o uso da variante "alveopalatal surda e sonora", enquanto os homens $(0,38)$ a desfavorecem. De acordo com Mollica e Braga $(2015$, p. 36), as mulheres tendem a liderar processos de mudança quando a variante inovadora é também a variante de prestígio. Desse modo, poderíamos supor que a variante "alveopalatal" por ser mais realizada pelas mulheres, seja a variante inovadora e a de prestígio, mas precisaríamos cruzar os resultados dessa variável com outras variáveis tais como idade, ocupação e mobilidade.

No que tange à variável extralinguística mobilidade, esta foi a terceira na escala das variáveis que mais favoreceram a aplicação da regra. Na Tabela 4, verificamos a seguir a probabilidade da variante "alveopalatal surda e sonora" de acordo com essa variável:

Tabela 4- Frequência e probabilidade da variante "alveopalatal surda e sonora", segundo a variável mobilidade

\begin{tabular}{l|c|c|c}
\multicolumn{1}{c|}{ Fatores } & Aplicação/ Total & \% & P.R \\
\hline $\begin{array}{l}\text { Pouca mobilidade: aqueles informantes que saíram da cidade so- } \\
\text { mente para viagens ao médico ou visitas aos parentes e amigos. }\end{array}$ & $312 / 393$ & $79,4 \%$ & 0,80 \\
\hline $\begin{array}{l}\text { Média mobilidade: aqueles informantes que moraram de um ano a } \\
\text { dois anos em outra cidade. }\end{array}$ & $193 / 291$ & $66,3 \%$ & 0,42 \\
\hline $\begin{array}{l}\text { Muita mobilidade: aqueles informantes que moraram mais de dois } \\
\text { anos em outra cidade ou comunidade ribeirinha pertencente a seu } \\
\text { município. }\end{array}$ & $2074 / 3202$ & $64,8 \%$ & 0,46 \\
\hline
\end{tabular}

Significância: 0,000

Input: 0,65

Fonte: autoria própria (adaptado do Relatório Final "Variação do /S/ em coda silábica no falar dos moradores da cidade de Tonantins (Amazonas)", realizado em 2018/2019).

Baseando-se nos resultados da Tabela 4, notamos que o fator pouca mobilidade $(0,80)$ é o que mais favorece a realização da variante "alveopalatal", enquanto os fatores média mobilidade e muita mobilidade a desfavorecem (0,42 e 0,46, respectivamente). Segundo Coelho et. al. (2012), o termo mobilidade se refere ao quanto uma pessoa se deslocou da sua "comunidade de fala" de origem. Dessa forma, a realização da variante "alveopalatal", nesta pesquisa, dá-se mais por aqueles indivíduos que não saíram muito da sua comunidade de origem. Por outro lado, é menos realizada por aqueles que, saindo da sua "comunidade de fala" por um tempo maior, tiveram maior contato com as variantes de comunidades de fala externas.

$\mathrm{Na}$ Tabela 5, a seguir, a fim de entendermos melhor o funcionamento do fenômeno em estudo, correlacionamos as variáveis sexo e mobilidade: 
Tabela 5- Frequência e probabilidade da variante “alveopalatal surda e sonora”, segundo o cruzamento das variáveis sexo $e$ mobilidade

\begin{tabular}{|c|c|c|c|}
\hline \multirow[b]{4}{*}{ 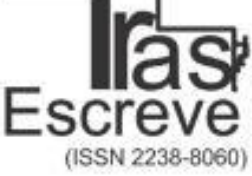 } & Mobilidade & Mulher & Homem \\
\hline & Pouca & $79 \%$ & $0 \%$ \\
\hline & Muita & $74 \%$ & $59 \%$ \\
\hline & Média & $66 \%$ & $0 \%$ \\
\hline
\end{tabular}

Fonte: autoria própria (adaptado do Relatório Final "Variação do /S/ em coda silábica no falar dos moradores da cidade de Tonantins (Amazonas)", realizado em 2018/2019).

Verificamos, na Tabela 5, que as mulheres são menos influenciadas pela variável mobilidade, pois tanto as que apresentam pouca mobilidade, quanto as que apresentam muita mobilidade utilizam com mais frequência a variante "alveopalatal" (79\% e 74\%, respectivamente), independente da influência de variantes externas à localidade. Ressalta-se que, nesta pesquisa, dentre as 6 mulheres entrevistadas, 4 apresentaram muita mobilidade. No que tange aos homens, todos os entrevistados apresentam muita mobilidade e parecem, assim, serem mais influenciados pelos contatos externos que tiveram durante o tempo que passaram longe de sua comunidade linguística de origem.

No que se refere à variável idade, esta foi a quarta dentre as variáveis independentes que favorecem o uso da variante "alveopalatal surda e sonora". Na Tabela 6, a seguir, verificaremos a influência da variável idade no uso da variante mencionada:

Tabela 6- Frequência e probabilidade da variante "alveopalatal surda e sonora", segundo a variável idade

\begin{tabular}{l|c|c|c}
\hline Fatores & Aplicação/ Total & $\mathbf{\%}$ & P.R \\
\hline 36 a 55 anos & $911 / 1365$ & $66,7 \%$ & 0,57 \\
\hline 18 a 35 anos & $735 / 1084$ & $67,8 \%$ & 0,51 \\
\hline Mais de 56 anos & $933 / 1437$ & $64,9 \%$ & 0,42 \\
\hline
\end{tabular}

Significância: 0,000

Input: 0,65

Fonte: autoria própria (adaptado do Relatório Final "Variação do /S/ em coda silábica no falar dos moradores da cidade de Tonantins (Amazonas)", realizado em 2018/2019).

Com bases no resultado da Tabela 6, observamos que a faixa etária intermediária (36 a 55 anos) foi a que mais favoreceu a aplicação da regra $(0,57)$, seguida da primeira faixa etária (18 a 35 anos, 0,51 ), enquanto a terceira faixa etária (mais de 56 anos) a desfavorece $(0,42)$. Ressalta-se que os valores de favorecimento da variante "alveopalatal" são muito próximos do ponto neutro.

A seguir, na Tabela 7, consideramos importante cruzar as variáveis idade e mobilidade com o intuito de compreender melhor o funcionamento da variável dependente aqui em estudo:

Tabela 7- Frequência e probabilidade da variante "alveopalatal surda e sonora", segundo o cruzamento das variáveis idade e mobilidade

\begin{tabular}{l|c|c|c|}
\hline \multicolumn{1}{c|}{ Mobilidade } & 1. $^{\text {a }}$ faixa etária & 2. $^{\text {a }}$ faixa etária & 3. $^{\text {a }}$ faixa etária \\
\hline Média & $67 \%$ & $0 \%$ & $0 \%$ \\
\hline Muita & $68 \%$ & $67 \%$ & $59 \%$ \\
\hline Pouca & $0 \%$ & $0 \%$ & $79 \%$ \\
\hline
\end{tabular}

Fonte: autoria própria (adaptado do Relatório Final "Variação do /S/ em coda silábica no falar dos moradores da cidade de Tonantins (Amazonas)", realizado em 2018/2019).

A partir dos resultados da Tabela 7, notamos que os informantes mais velhos com pouca mobilidade usam com maior frequência a variante "alveopalatal" (79\%). No entanto, ressalta-se que só houve um (1) informante que apresentou pouca mobilidade e era do sexo feminino. Como observamos na correlação feita na Tabela 5, entre sexo e mobilidade, as mulheres parecem sofrer menos influência de variantes externas à localidade. Por outro lado, em relação ao fator muita mobilidade, os mais velhos realizam com menos frequência a variante em discussão (59\%), enquanto os mais jovens utilizama com maior produtividade ( $1^{a}$ faixa etária: $68 \%$; $2^{a}$ faixa etária: $67 \%$ ). Isso nos mostra também que os mais jovens, assim como as mulheres, parecem receber menos influências de variantes de outras 
comunidades linguísticas e/ou podemos levantar como hipótese que a variante "alveopalatal" possa ser uma variante inovadora na cidade em estudo.

$\mathrm{Na}$ Tabela 8, a seguir, consideramos importante correlacionar idade e sexo para entendermos quem está liderando a mudança, assim como pensarmos se está em jogo o valor de prestígio ou não do fenômeno em estudo.

Tabela 8- Frequência e probabilidade da variante "alveopalatal surda e sonora", segundo o cruzamento das variáveis idade e sexo

\begin{tabular}{l|c|c}
\hline \multicolumn{1}{c|}{ Mobilidade } & Mulher & Homem \\
\hline $1^{\text {a }}$ faixa etária & $67 \%$ & $69 \%$ \\
\hline $2^{\mathrm{a}}$ faixa etária & $75 \%$ & $61 \%$ \\
\hline $3^{\mathrm{a}}$ faixa etária & $78 \%$ & $51 \%$ \\
\hline
\end{tabular}

Fonte: autoria própria (adaptado do Relatório Final "Variação do /S/ em coda silábica no falar dos moradores da cidade de Tonantins (Amazonas)", realizado em 2018/2019).

O que se observa na Tabela 8 é que a variante "alveopalatal” é mais utilizada por homens da primeira e segunda faixa etária (69\% e 61\%, respectivamente), do que pelos de terceira faixa etária (51\%). Por outro lado, as mulheres mais velhas (segunda: $75 \%$ e terceira faixa etária: $78 \%$ ) são as que mais utilizam a variante em questão do que as de primeira faixa etária (67\%). Esse resultado pode revelar que um possível processo de mudança parece estar sendo liderado por homens e que, provavelmente, essa variante não seja considerada de prestígio, já que homens, nos estudos sociolinguísticos já realizados, mostram-se liderar a mudança linguística quando a variante não é considerada de prestígio. No entanto, como a variável escolaridade não foi selecionada pelo programa estatístico, é delicado falarmos em valor de prestígio X estigma em relação ao uso do /S/ em coda silábica em Tonantins (AM).

No que diz respeito à variável ocupação, esta foi a última variável que se mostrou mais favorável à aplicação da regra. Vejamos na Tabela 9 a realização da variante "alveopalatal" de acordo com essa variável:

Tabela 9- Frequência e probabilidade da variante "alveopalatal surda e sonora", segundo a variável ocupação

\begin{tabular}{l|c|c|c}
\multicolumn{1}{c|}{ Fatores } & Aplicação/ Total & \% & P.R \\
\hline Média: autônomo (comércio). & $269 / 343$ & $78,4 \%$ & 0,60 \\
\hline $\begin{array}{l}\text { Baixa: Agricultor, dona de casa, auxiliar de serviços gerais, } \\
\text { pescador. }\end{array}$ & $1733 / 2674$ & $64,8 \%$ & 0,52 \\
\hline Alta: professor, professor aposentado. & $577 / 869$ & $66,4 \%$ & 0,37 \\
\hline
\end{tabular}

Significância: 0,000

Input: 0,65

Fonte: autoria própria (adaptado do Relatório Final "Variação do /S/ em coda silábica no falar dos moradores da cidade de Tonantins (Amazonas)", realizado em 2018/2019).

Verificamos que o fator ocupação média $(0,60)$ foi o que mais favoreceu o uso da variante "alveopalatal surda e sonora", seguido do fator ocupação baixa $(0,52)$, enquanto o fator ocupação alta a desfavorece $(0,37)$. Podemos, assim, levantar como hipótese, mais uma vez, que essa variante possa não ser considerada de prestígio em Tonantins, já que os informantes considerados de profissão de cotação mais alta ${ }^{20}$ não a utilizaram com tanta produtividade.

\section{Considerações finais}

Conforme proposto, descrevemos e analisamos a variação do /S/ em coda silábica no mu-

20 Destaca-se que apenas dois (2) informantes se encaixaram nesse perfil (professor e professor aposentado). Assim, a maioria dos entrevistados enquadrou-se no fator ocupação baixa (agricultor, dona de casa, auxiliar de serviços gerais, pescador). 
nicípio de Tonantins (AM) a fim de ampliar o estudo sobre a área dialetal mencionada. Os resultados mostraram, de maneira geral, que a variante "alveopalatal" foi a mais realizada $(66,3 \%)$, seguida da variante "alveolar" $(25,7 \%)$. Relacionando a realização da variante "alveopalatal" com as variáveis independentes controladas, concluiu-se que as variáveis mais favoráveis foram: contexto seguinte, sexo, mobilidade, idade e ocupação.

Vale ressaltar que, no geral, os resultados deste estudo se aproximam dos resultados de R. Maia (2016/2017), visto que, nos municípios de São Paulo de Olivença e Tonantins, ambos pertencentes à microrregião do Alto Solimões, realizou-se mais a variante "alveopalatal surda e sonora" e, portanto, vão de encontro aos resultados encontrados por Melo (2017/2018), a qual encontrou a variante "alveolar" como a mais frequente em Jutaí (também pertencente ao Alto Solimões, na divisão feita pelo IBGE, 2010).

Verificou-se, com isso, que os resultados deste trabalho e os de R. Maia (2016/2017) não atestam a hipótese levantada por Cruz (2004), já que para essa microrregião, através do município Benjamin Constant, a referida pesquisadora apontou a "alveolar" como a mais produtiva. Dessa forma, somente os resultados de Melo (2017/2018) confirmaram a hipótese de Cruz (2004).

Dado o exposto, esperamos ter contribuído com os estudos sobre o fenômeno /S/ em coda silábica no PB e, também, termos ampliado o conhecimento sobre a área dialetal estudada, no caso Tonantins, no Amazonas.

\section{REFERÊNCIAS}

BASSI, A. A palatalização da fricativa em coda silábica no falar florianopolitano e carioca: uma abordagem fonológica e geolinguística. 2011. 192 f.; Dissertação (Mestrado em Linguística) Universidade Federal de Santa Catarina, Florianópolis, 2011.

BRAGA, M.; MOLLICA, M. Introdução à Sociolinguística: o tratamento da variação. 4. Ed. São Paulo: Contexto, 2015.

BRESCANCINI, C. R. A representação lexical das fricativas palato-alveolares: uma proposta. Revista Letras, Curitiba, n. 61, especial, p. 299-310, 2003.

BRITO, R. M. Atlas dos falares do baixo Amazonas - AFBAM. 2011. 297 f. Dissertação (Mestrado em Sociedade e Cultura na Amazônia) - Universidade Federal do Amazonas, Manaus, 2011. CALLOU, D.; MORAES, J. A. A norma da pronúncia do S e do R pós-vocálicos: distribuição por áreas regionais. In: Diversidade linguística e ensino. Org. Suzana Cardoso. Salvador: EDUFBA, 1996.

CANOVAS, M. I. F. 1991. Variação fônica de /S/ pós-vocálico e de /s, z, $\square$ / cabeças de sílaba na fala de salvador. In: Diversidade linguística e ensino. Org. Suzana Cardoso. Salvador: EDUFBA. CARDOSO, M.; MAIA, E.; MARTINS, F. Reflexões sobre a variação do /S/ em coda silábica no falar amazonense: a hipótese de uma isófona. Revista Sociodialeto-silábica, v. $7, n^{\circ}$ 20, p. 479502, nov-fev. 2017.

COELHO, I. L. [et. al.]. Para Conhecer Sociolinguística. São Paulo: Contexto, 2015.

CRUZ, M. L. C. Atlas Linguístico do Amazonas- ALAM. 2004. 159 f. Tese (Doutorado em Letras Vernáculas) - Universidade Federal do Rio de Janeiro, Rio de Janeiro, 2004.

FREITAG, R. M. K. (Re)discutindo sexo/gênero na Sociolinguística. In: Freitag, Raquel Meister Ko.; Severo, Cristine Gorski (Org.). Mulheres, Linguagem e Poder- Estudos de Gênero na Sociolinguística Brasileira. São Paulo: Blucher, 2015, p.17-74.

GUY, Gregory R.; ZILLES, Ana. Sociolinguística Quantitativa: instrumental de análise. São Paulo: Parábola, 2007.

HORA, D. D. Variação fonológica: consoantes em coda silábica. João Pessoa, 2000.

JESUS, C. S.; MOTA, J. A. A variação fonética no português do Brasil: diferenças diatópicas na realização do /S/ em coda silábica, a partir dos dados do Atlas Linguístico do Brasil (AliB). Apresentado no Seminário Estudantil de Pesquisa do Instituto de Letras da Universidade Federal da 
Bahia, Salvador, 2006.

LABOV, W. 2008 [1972]. Padrões sociolinguísticos. Trad. De Marcos Bagno; Maria Marta Scherre; Caroline Cardoso. São Paulo: Parábola.

MAIA, E. G. Realização fonética do /S/ pós-vocálico nos municípios de Boca do Acre, Lábrea e Tapauá. 2012. 254f.; Dissertação (Mestrado em Letras) - Universidade Federal do Amazonas, Manaus, 2012.

MAIA, R. B. Variação do /S/ em coda silábica no falar dos moradores de São Paulo de Olivença (Amazonas). Benjamin Constant: 2016.

MELO, K. B. Variação do /S/ em coda silábica no falar dos habitantes do município de Jutaí (Amazonas). Manaus: 2018.

MARTINS, A. F. C. A pronúncia do fonema /S/ e suas variações no português do município de Bragança. Relatório Técnico Científico. Programa de Pesquisa e Pós-graduação. Departamento de Pesquisa. Programa Institucional de Bolsas de Iniciação Científica PIBES e PIBIC. Agosto (2000) a julho (2001), 2001.

MARTINS, F. S. A pronúncia do -S pós-vocálico nos municípios de Itacoatiara, Manacapuru, Parintins, Tefé, Barcelos e Benjamin Constant. XVI Congresso de Iniciação Científica da UFAM, 30 de julho a 3 de agosto, Manaus, 2007.

MARTINS, F. S. Variação na concordância nominal de número da fala dos habitantes do Alto Solimões (Amazonas). 2013. 222 f. Tese (Doutorado em Linguística) - Faculdade de Letras, Universidade Federal de Santa Catarina, Florianópolis, 2013.

MARTINS, F. MARGOTTI, F. Comportamento fonético-fonológico do /S/ pós-vocálico em Manaus. Revista Investigações, v. 25, n. 2, p. 249-274, julho. 2012.

QUARA, H. R. G. Comportamento fonético-fonológico do -S pós-vocálico nos falares dos municípios de Eirunepé, Lábrea e Humaitá do Amazonas. Manaus: UFAM, Relatório de pesquisa e iniciação científica (PIBIC), 2007.

SCHERRE, M. M. P.; MACEDO, A. T. 1991. Variação e Mudança: o caso da pronúncia do S pósvocálico. In: ABRALIN. Associação Brasileira de Linguística. No 11, Junho.

SILVA NETO, S. A língua portuguesa no Brasil. Separata da Revista de Portugal - Série A Lingua Portuguesa. vol. XXV. Lisboa: Editorial Império, 1960.

SILVA, T. C. Fonética e fonologia do português: roteiro de estudos e guia de exercícios. 7. Ed. São Paulo: Contexto, 2003.

SMAICLOVÁ, G. Palatalização do /S/ em coda silábica no português falado na Costa da Lagoa em Florianópolis. Work. Pap. Linguística, Florianópolis, n. esp., p. 33-44, 2010.

WEINREICH, U.; LABOV, W.; HERZOG, M. Fundamentos empíricos para uma teoria da mudança linguística. Trad. de Marcos Bagno. São Paulo: parábola editorial, 2006 [1968]. 